\title{
A América Latina indivisível: a influência do positivismo no projeto intelectual de José Enrique Rodó
}

ELISÂNGELA DA SILUA SANTOS*

\section{Resumo}

Neste artigo, temos como objetivo fazer uma análise da influência do positivismo comtiano no pensamento do autor uruguaio José Enrique Rodó (18711917). Rodó escreve num momento marcado pela necessidade de um reajuste histórico na América Latina; sua lição se dirige aqueles homens que deveriam retomar as rédeas da sociedade, a fim de inspirá-los por meio de uma disciplina intelectual que devolvesse a cultura dos valores de espírito perdidos com o avanço da ordem capitalista. Podemos notar que a influência do positivismo no pensamento de Rodó se apresenta a partir dos seguintes aspectos: uma visão generalizada sobre a sociedade Latino-Americana, vista como conjunto uno e indivisível, a organização mental, a importância da atividade intelectual como responsável pela avaliação da história progressiva do espírito humano, o conhecimento como intervenção social; também a ausência de oposição entre a ciência e a religião.

Palavras-chave: Positivismo; José Enrique Rodó; Auguste Comte; Intelectualidade; Pensamento tradicional.

\footnotetext{
* Universidade Federal de Goiás, Regional Jataí.
} 


\section{The indivisible Latin America: the influence of positivism on the intellectual project of José Enrique Rodó}

\section{Abstract}

This article aims to analyze the influence of Comte's positivism in the thinking of the Uruguayan author José Enrique Rodó (1871-1917). Rodó writes in a period marked by the need for a historical readjustment in Latin America; his lesson addresses those men who should take over the reins of the society, in order to inspire them through an intellectual discipline able to give back the culture of spiritual values lost with the advance of the capitalist order. We can notice that the influence of positivism in Rodó's thinking appears in the following aspects: a generalized view of the Latin American society, seen as one and an indivisible whole, the mental organization, the importance of the intellectual activity as an instrument responsible for assessing the progressive history of the human spirit, the knowledge as a social intervention; also the absence of opposition between science and religion. Keywords: Positivism; José Enrique Rodó; Auguste Comte; Intellectuality; Traditional thinking.

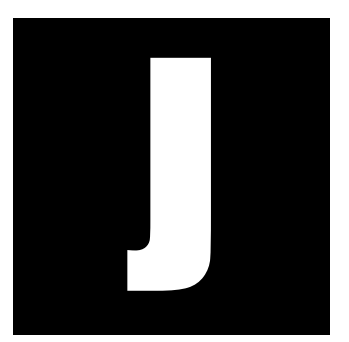

osé Enrique Rodó (1871-1917) nasceu em Montevidéu/ Uruguai; aos 29 anos publicou Ariel, obra que o fez conhecido por toda a América Latina e Espanha. Além de escritor, jornalista, crítico literário, também atuou como político em seu país, desempenhando o cargo de deputado. Produziu seus principais textos num momento histórico que delimitava a formação da chamada inteligência latino-americana, que por sua vez, era marcada por influências bastante ecléticas entre o final do século XIX e início do século XX. 
A obra de José Enrique Rodó no Brasil ainda é pouco difundida e também pouco discutida. A maioria da fortuna crítica brasileira sobre este autor está localizada no contexto da primeira metade do século XX. Segundo Juan Pebet Sabat (1931), desde os anos 30 os textos de Rodó deixaram de ser lidos e citados com a mesma intensidade que seus escritos tiveram nas duas primeiras décadas do século XX em seu país de origem. Pebet observava que, ao deixar de lado os escritos de Rodó, o Uruguai moderno perdia um de seus mais importantes pensadores. Rodó manteve contato com importantes intelectuais brasileiros, dentre eles José Veríssimo (1857-1916) e Vicente Licínio de Cardoso (1890-1931).

No contexto uruguaio, Rodó desempenhou a "dimensão prática" da figura do intelectual - em toda a sua vida esteve envolvido na vida política de seu país. Em 1898, trabalhou no Jornal El Orden e atuou como militante do Partido Colorado. Em 1900, participou do movimento da Juventude Colorada, que almejava a união das diversas facções de seu partido, a renovação da política partidária e da política nacional, a mudança do sistema presidencial pelo parlamentarista, a representação proporcional, o voto secreto e a descentralização eleitoral. Além disso, por três períodos, foi eleito deputado por Montevideo (1902-1905), (1907-1911) e (19121915). Durante este período atuou e representou com autoridade moral e prestígio o seu papel no poder político.

No contexto latino-americano, Rodó enfrentou intensamente o dilema da definição da identidade latino-americana. Para ele, esta deveria fundamentar-se na herança clássica greco-latina, cimentada nos valores espirituais e na cultura. Em suas principais obras: Ariel (1900), Motivos de Proteo (1909) e El mirador de Próspero (1913), Rodó realizou um diagnóstico sobre a situação cultural e social do continente latino e também concretizou um "projeto" de integração dos países que descendiam da Ibero-América. 
A formação intelectual rodoniana é marcada por uma gama de autores, desde os franceses, passando pelos alemães e finalmente chegando aos espanhóis. Dessa forma, ao apontarmos as ressonâncias do positivismo de Auguste Comte em sua obra, não queremos afirmar que este clássico autor da sociologia foi a única influência filosófica europeia que Rodó teve, mesmo porque Rodó faz parte de uma geração de autodidatas que se esforçava intelectualmente para esboçar uma cultura específica no novo continente, mediante as grandes transformações sociais do momento.

A Rodó interessava debater como se daria a transição entre Europa e América, uma vez que o novo mundo deveria se constituir e estabilizar como um "solo fértil de ideias", para tanto, a aposta em teorias europeias já consolidadas. Mas, como deveria ocorrer este encontro entre continentes tão distintos? A proposta rodoniana parte da ideia de equilíbrio entre as diferentes partes: assim como a pátria filha esperava muito da pátria mãe, esta também podia esperar contribuições do novo continente, que até então representava uma "humilde pinta no mapa", mas era uma raça capaz de produzir uma personalidade própria. Conforme as interpretações dos autores desse momento, a vida intelectual na América Latina poderia conferir densidade e complexidade suficientes, passando a ser regida como uma coletividade social distinta da lógica vigente na antiga metrópole, por exemplo.

Nesse momento em que Rodó escreve, há um contínuo intercâmbio crítico com ideologias do Ocidente industrial. Para Morse (2011), muitos pensadores, concordaram com as receitas vigentes de "progresso" e reconheceram com pesar o atraso de seus países. O objetivo comum seria "inventar uma nova realidade", um novo futuro. Entretanto, essas ideologias não chegavam aos pensadores de forma homogênea e nem ordenada. Sim de forma caótica, contraditória e incerta. Sobre as influências contraditórias das leituras realizadas, Rodó escreveu um artigo homônimo enfeixado em Nuevos Motivos de Proteo (1911), fazendo o seguinte comentário: 
Hay veces en que las influencias contradictorias de lecturas igualmente intensas, que comparten la afición y el hábito, que entrecruzan en un espíritú, sin ceder las unas a las otras, y persisten en un vivo conflicto, determinando para la vida entera de aquél una especie de duplicidad. (RODÓ, 1957, p. 903)

Nesse sentido, discutiremos alguns aspectos de uma das principais correntes filosóficas que foi bastante debatida por Rodó em seus escritos: o Positivismo. Primeiramente, faremos uma breve apresentação da forma como Rodó concebe tal filosofia. Veremos que sua interpretação se distingue da de muitos pensadores latino-americanos deste momento, uma vez que Rodó não buscava nessa corrente de pensamento a ideia de progresso material e científico, sim o sentimento de idealidade e o "aprimoramento das mais nobres faculdades mentais". Num segundo momento, retomaremos o culto rodoniano ao passado, para ele o Cristianismo e o Classicismo grego eram as duas correntes que mais contribuíram para a construção dos ideais estéticos e éticos dos homens. Entende-se aqui a forte influência comtiana com relação ao catolicismo. Num terceiro momento, discutiremos a ideia de Rodó no que concerne aos chamados diferentes governos presentes na humanidade, o espiritual e religioso e o material humano. Nesse ponto, há uma clara herança da divisão realizada por Comte entre o físico e o moral.

Segundo Alberto Zum Felde (1927), a América Latina respondeu sempre às mudanças produzidas na consciência ocidental - foi romântica, realista, simbolista, idealista, positivista - quase de modo passivo. Portanto, ao aprofundarmos no estudo dessa corrente de pensamento presente na reflexão rodoniana, devemos atentar para o fato de que o positivismo chegava até os autores latino-americanos como sinônimo de modernidade e ocidentalidade, numa espécie de aspiração à civilização e negação da barbárie. Desse modo, o positivismo cumpria duplo papel na América Latina: 1) organizar ideologicamente as nascentes democracias nacionais, 
2) e prover aos latino-americanos um sistema de ideias e costumes que superasse as formas sociais e psicológicas consideradas antigas, ideias e modos de vida novos que estimulassem o progresso material e os hábitos industriosos de seus habitantes. Somente assim haveria uma organização do caos que a Colônia vivia após a Independência.

Para Richard Morse (1982), a questão que surge na independência ibero-americana não é a esquizofrenia da intelectualidade, dilacerada entre as visões de mundo ibérica e anglo-francesa. Nenhuma das duas versões, nem a mistura de ambas, podia oferecer uma ideologia "hegemônica" que encontrasse aceitação, ou mesmo aquiescência passiva nessas sociedades.

A chamada Geração dos 900 uruguaia, a qual incorpora o pensamento de Rodó, estava em busca dessa definição para a América Latina. A cultura dessa época estaria desorientada e contingente, babélica e espiritualmente desvalorizada; seria o que ele chamou de la verdad inarmónica que es el signo característico de la transición. No caso, a experiência comum fundamental dessa geração foi o modernismo. Segundo Monegal (1950), o objetivo de Rodó não foi discutir fórmulas para resolver os chamados problemas cotidianos do continente, sim preferiu concentrar sua análise em problemas que estavam um pouco esquecidos na América Latina: a descoberta e a conquista da vocação pessoal, o aperfeiçoamento da espiritualidade, a concepção de pátria americana projetada para o futuro.

Para Belém de Castro Morales (1988), o fato de essa geração não possuir um "sistema prévio" de pensamento, significava a carência de parâmetros que ordenassem, dentro dos cânones racionalizados e organizados, os logros da experiência filosófica e artística. Também significava o triunfo da liberdade individual, da iniciativa pessoal, da livre interpretação do mundo conforme princípios íntimos (subjetivos) e não exteriores (sistemáticos e objetivos). Os ensaios produzidos nesse momento mostram 
as diferentes facetas discursivas em diversos campos de conhecimento: na literatura, na estética, no pensamento filosófico e político, na crítica de cultura etc.

Lemos em Rodó uma incessante busca para consolidar no Continente uma literatura, uma cultura e um pensamento filosófico:

En medio de su soledad, nuestras almas se sienten dóciles, se sienten dispuestas a ser guiadas; y cuando dejamos pasar sin séquito al maestro que nos ha dirigido su exhortación sin que ella moviese una onda obediente en nuestro espíritu, es para luego preguntarnos en vano con Bourget: "¿Quién hay de pronunciar la palabra de porvenir y de fecundo trabajo que necesitamos para dar comienzo a nuestra obra? ¿quién nos devolverá la divina virtud de la alegría en el esfuerzo y la esperanza de la lucha? (RODÓ, 1957, p. 150)

Neste texto, La vida nueva - el que vendrá, publicado originalmente em 1896, Rodó questiona o que virá e o que acontecerá com a arte e com o pensamento da América Latina, fala em solidão (aludindo à orfandade do continente que deixara de ser colônia), da docilidade das almas que estão dispostas a serem guiadas, daí a necessidade de se filiar a um esquema filosófico já solidificado, pois o continente necessitava começar sua obra.

Esse processo de criação de uma filosofia reclamado por Rodó para as antigas colônias, buscou respaldo na filosofia ocidental. O positivismo foi a primeira filosofia acolhida amplamente. O positivismo também se sustentava na América Latina por ser uma reação contra a teologia e uma filosofia difusa em nome da ciência. Ao mesmo tempo, a crença no progresso material baseado no desenvolvimento científico e o utilitarismo eram vistos como sistemas adequados para a vida industrial. Desse modo, a doutrina de Auguste Comte (1798-1857) influenciou como método, como reação à teologia e a metafísica, e como uma direção pedagógica.

Como veremos, esta acolhida do positivismo passou na América Latina por um processo de ressignificação; característica que veremos mais 
de perto a partir do pensamento rodoniano, que estava em busca de uma definição da especificidade do nosso pensamento, e ao mesmo tempo, procurando a universalidade na cultura europeia'.

É importante situar brevemente o leitor brasileiro com relação à importância que a filosofia positivista também assumiu no contexto de formação das nossas ideias, compreendendo que as realidades nacionais foram responsáveis por reconstruções históricas distintas em relação às correntes de pensamento. A filosofia positivista no Brasil, atingiu força e relevo enquanto filosofia, a partir das últimas décadas do século XIX. Foi nesse contexto que se forjou uma nova definição do espaço institucional da ciência e dos papéis sociais do cientista. Além disso, o positivismo também teve grande importância na implantação da República no Brasil e se expandiu de forma intensa na universidade, como a filosofia capaz de oferecer o "progresso científico da nação". A influência desta filosofia se estendeu por toda a formação cultural brasileira, na medida em que fundamentou as concepções de modernidade entre os fins do século XIX e início do XX, além de atuar como suporte ideológico e fundamental no projeto de construção e afirmação de uma ordem social no Brasil e de definição do científico como forte componente do ideário da inteligência brasileira.

\footnotetext{
${ }^{1}$ Conforme algumas interpretações, como as realizadas pela geração espanhola de 1898, a dupla gênese oriental/ocidental já estava presente na Península Ibérica. O último terço do Século XIX espanhol é um dos momentos mais significativos de uma longa crise da relação entre Espanha e Europa. O grande debate trazido por essa geração nesse momento era a europeização ou não do país. Fez parte dessa geração o filósofo, ensaísta e intelectual espanhol Miguel de Unamuno (1864-1936), Antonio Machado (1875-1939), Azorín (1873-1967) e outros. A discussão que estes autores trouxeram dizem respeito ao atraso espanhol com relação ao restante do continente europeu. Para eles a Europa se mostrava burguesa em sua plenitude, na Espanha não havia nem indústria, nem ciência e nem pensamento liberal. Segundo Dardo Cúneo (1997), 1898 é a data do desastre imperial, momento em que a Espanha perde suas últimas colônias, é também o ano do fracasso militar que abre espaço para a meditação, o retorno da história espanhola para seu centro peninsular, momento em que voltam a olhar em seus próprios espelhos.
} 
Os intelectuais que se filiaram ao positivismo no Brasil, de acordo com João Cruz Costa (1956), não eram apenas os herdeiros dos senhores dos engenhos ou dos fazendeiros de café, eram representantes e herdeiros, em grande parte, da burguesia de comerciantes ou de burocratas, que surgiu nas aglomerações urbanas e que na metade do século XIX teve maior expressão e sentido, devido às transformações econômicas; foi principalmente nas Faculdades de Direito do país que se filiavam esses novos burgueses.

Foi a partir de 1870 que esta nova burguesia assumiu papel de importância no setor intelectual. Era formada por militares, médicos e engenheiros: tratava-se de homens que se voltaram para a ciência e que nela acreditavam encontrar respostas satisfatórias e soluções definitivas para outros problemas. A chamada geração de intelectuais de 1870 (que incluía nomes como Eduardo Prado, Joaquim Nabuco etc), desenvolveu a ideia de que o país praticava uma vida ideológica deslocada, por imitação e moda dos costumes europeus, e que o motivo desta prática era o espirito desfibrado do brasileiro.

A palavra de ordem desta geração era condenar a sociedade "fossilizada" do Império e pregar as grandes reformas redentoras: "a Abolição", "a República", "a Democracia". Para esses intelectuais, cujo engajamento significava fator importante para o desenvolvimento do país, a tradição científica implantada no Brasil foi livresca, em oposição à cultura moderna e científica, uma cultura de submissão à autoridade e não do respeito à razão, uma cultura de conservação da ordem social e não da mobilidade e transformação das estruturas sociais.

Por isso a necessidade de institucionalização no país de uma educação de "índole científica", neste caso, era preciso reformar o ensino superior responsável pela formação de uma nova elite intelectual dotada de ethos científico diferente dos hábitos intelectuais da cultura jurídica/ literária dos bacharéis. 
Segundo Lippi Oliveira (1990), os intelectuais que escreveram entre 1870 a 1914 tinham como objetivo uma atualização da modernização brasileira. Queriam iluminar o país através da ciência e da cultura; somente esta reação científica poderia auxiliar na evolução da nação.

A elite intelectual aceitou aquelas ideias que permitiam pensar a integração do Brasil na cultura ocidental. O positivismo, o darwinismo, o spencerismo e o materialismo preencheram o mesmo papel; essas correntes veicularam uma filosofia da história que possibilitava esta integração ao moderno, ao científico, ou ao Estado positivo. (OLIVEIRA, 1990, p. 82)

O positivismo comteano foi uma das expressões mais marcantes deste cientificismo de tendência cosmopolita, uma vez que o país necessitava acompanhar o ritmo do capitalismo internacional. Por isso, temas como ciência, raça e civilização deveriam fazer parte dos valores nacionais, uma vez que tais valores eram os sustentáculos europeus sobre o mundo até a Primeira Guerra Mundial. Foi nesse momento, também, que as teorias evolucionistas, cientificistas e darwinistas começaram a fazer parte da bagagem teórica do intelectual brasileiro. Entretanto, eram modelos utilizados de diferentes maneiras pelos intelectuais, o que forneceu uma diversidade sobre a forma de encarar a nossa "evolução cultural".

Nesse sentido, é válida a observação de Mannheim (1982), quando este afirma que até mesmo a filosofia passa por diferentes mudanças, tanto orgânica quanto de estrutura, implicando na existência de alguma ideia da relação que apresentam entre si as filosofias de diferentes épocas:

Em outras palavras, precisamos ter alguma ideia que nos identifique se as diferentes filosofias se destroem mutuamente, ou se elas se desenvolvem conjuntamente, por assim dizer, em uma divisão supratemporal do trabalho, como partes últimas de um sistema inacabado. Ou, ainda, se elas são constantemente reconstruídas, partindo de novos centros ainda mais abrangentes, de tal forma que as velhas in- 
terpretações são incorporadas às novas e revestidas de um novo significado (MANNHEIM, 1982, p. 144).

Assim compreendida a influência de correntes europeias no pensamento social latino-americano, podemos dizer que as correntes de ideias não fluíram e se avolumaram a partir de canais separados. O autor de Ariel tentava procurar referências num passado que a América Latina não possuía, porém herdava a partir do processo de colonização. Segundo Zea (2005), a América Latina não criou metafísicas e sistemas filosóficos, mas adotou as que foram criadas na cultura europeia, adaptando-as à sua realidade política e social.

\section{O Positivismo em Rodó}

Arturo Ardao (1968), em seu livro Espiritualismo y positivismo en Uruguay, afirmou que o positivismo trouxe ao Uruguai uma verdadeira revolução cultural, sem semelhante na história. Gerou um aprofundamento do cientificismo, significou uma mudança essencial dos conteúdos da inteligência nacional e influenciou principalmente como filosofia pedagógica e política.

Para Rodó, o positivismo na América Latina foi interpretado de maneira bastante equivocada e pobre:

El positivismo del siglo XIX tuvo esa multiforme y sistemática reencarnación; y así como en el orden de la ciencia condujo a corroborar y extender el método experimental, y en la literatura y arte llevó al realismo naturalista, así, en lo que respecta a la realidad política y social, tendió a entronizar el criterio utilitario, la subordinación de todo propósito y actividad al único o supremo objetivo del interés común. La oportunidad histórica con tal "forma original de espíritu" se manifestaba, es evidente; ya en el terreno de la pura filosofía, donde vino a abatir idealismos agotados y estériles, 
Sociologias, Porto Alegre, ano 17, no 40, set/dez 2015, p. 380-414

ya en el de la imaginación artística, a la cual libertó, después de la orgia de los románticos, de fantasmas y quimeras (RODÓ, 1957, p. 502.)

Rodó, retomando Comte, afirma que este pensava sobre as questões de intelectualidade e de moralidade. Seria uma insensatez substituir a qualidade por quantidade, portanto, considerar o positivismo apenas uma ciência quantitativa e evolucionista na América Latina, como muitas vezes ocorreu, era muito prejudicial às formas de desenvolvimento espiritual².

Rodó, conforme Gonzalo Zaldumbide (1967), propunha a reconciliação do positivismo com o idealismo: Aunque sus bases filosóficas sean positivistas, no profesa el positivismo como un sistema exclusivo; siempre mantiene puertas y ventanas abiertas al humanismo tradicional (ZALDUMBIDE, 1967, p. 49).

Segundo Lelita Benoit (1999), quando Comte adere ao paradigma teórico da ciência da história, vai entender que o poder espiritual se sobressai devido à sua capacidade de estabilizar a sociedade. Pretendia, inicialmente, fundamentar o positivismo a partir daquilo que é abstrato.

"Desrespeitar a temporalidade natural", tentar "queimar o tempo", eis a essência das revoluções políticas. Enquanto não se conseguir perceber o papel do tempo na história, enquanto se fizerem tentativas no sentido de "forçar a marcha lenta dos séculos", viveremos em um estado de revolução permanente. Para Comte, não havia dúvidas de que caminhamos para um regime completamente oposto ao antigo, um regime

\footnotetext{
${ }^{2}$ José Pedro Varela (1845-1879), pensador uruguaio que dedicou grande parte da sua obra à educação pública no país, preconizava uma reforma universitária que adotasse o modelo ideológico positivista, inspirado na filosofia de Comte. Conforme Fernando Mañe Garzón (1990), em algumas passagens da obra Ariel, de Rodó pode-se perceber a influência do conceito de seleção natural. Son varias las aplicaciones que hace de él: el valor selectivo de la belleza en los animales como necesidad de todo progreso (social, se entiende), como factor real de selección espiritual, preeminencia de los más aptos, logrando la realización en el seno de las sociedades humanas hasta el más crudo triunfo del struggle for life. (GARZÓN, 1990, p. 173).
} 
que será positivo e industrial; no entanto, é absolutamente impossível que suceda o outro subitamente (BENOIT, 1999, p. 128-9).

A Rodó preocupava justamente essa sucessão súbita de regime. A América Latina, após o processo de Independência da Hispano-américa, se transformou em sociedades divididas e esquartejadas. A Independência do continente, como afirmou Weffort (1990), instaurou o sentimento de "perda" de lugar no mundo, e a ideia de integração passou a ser a condição que mais definia o continente. Para o pensador uruguaio, a república que sonhava José Martí (1853-1895) estaria erigida na ideia de liberdade, prosperidade e paz, porém também era inteligência, cultura e idealismo:

Otra alentadora afirmación permite hacer la manera como este primer siglo concluye. $Y$ es que los pueblos hispanoamericanos comienzan a tener conciencia, clara y firme, de la unidad de sus destinos; de la inquebrantable solidariedad que radica en lo fundamental de su pasado y se extiende a lo infinito de su porvenir. Augusto Comte expresaba su profunda fe en la futura conciencia de la solidariedad humana, diciendo que la humanidad, como ser colectivo, no existe aún, pero existirá algún día. (RODÓ, 1957, p. 553).

Rodó projetava, a partir de sua crítica de arte e do seu pensamento filosófico, formar a pátria continental, vasta e una, e o termo americanismo faria a junção das diversas ideias presentes no Continente, que até então estavam esquartejadas, desorientadas; por isso utiliza-se do conceito comtiano de humanidade. Um dos alertas de Comte era de que cada vez mais a sociedade, conforme progredia, ia perdendo causas e destinos comuns. E os diversos órgãos da humanidade cada vez menos se preocupavam com os demais, concentrando-se nos seus próprios interesses, deixando de lado a sociabilidade e o altruísmo, tornando-se cada vez mais egoístas. Portanto, haveria a necessidade de um órgão coletivo que mantivesse a união social, e esse órgão seria o governo, que exerceria função primordial nessa unidade e na regulação do egoísmo dos indivíduos. 
Em 1826, no ensaio intitulado Considerações sobre o poder espiritual, Comte apresentou uma história do poder espiritual desde o Egito e do Oriente, passando pelos povos antigos e romanos; depois remete à Idade Média, época que, conforme ele, foi de suma importância para a moderna teoria social. A Idade Média teria legado à moderna teoria social a concepção política mais perfeita que jamais existiu, aquela da existência de dois poderes completamente separados e distintos: o poder temporal e o espiritual.

Esse reconhecimento da filosofia comtiana do poder espiritual pode ser percebido também no pensamento de Rodó. Conforme Ardao (1971), nos escritos do autor uruguaio há um forte instinto de equilíbrio intelectual, pensamento abstrato, porém conforme a experiência vital:

Es indudable, además, que si el espíritu positivista se saborea en las fuentes, en las cumbres, un Comte o un Spencer, un Taine o un Renan, la soberana calidad del pensamiento y la alteza constante del punto de mira infunden un sentimiento de estoica idealidad, exaltador, y en ningún caso depresivo, de las más nobles facultades y las más altas aspiraciones. Pero sin detenernos a considerar de qué manera y en qué grado pudo el positivismo degenerar o estrecharse en la conciencia europea, como teoría y como aplicación, y volviendo la mirada a nuestros pueblos, necesario es reconocer que aquella revolución de las ideas fue, por lo general, entre nosotros, tan pobremente interpretada en la doctrina como bastardeada en la práctica. (RODÓ, 1957, p. 502-3).

Percebe-se que, na visão de Rodó, este positivismo estreito, o qual na maioria das vezes havia prosperado na América Latina, não seria detentor dos verdadeiros valores a serem cultivados no continente. $\mathrm{O}$ interesse consagrado deveria possuir um fim espiritual, não material e utilitário da civilização. Em seu texto La tradición intelectual argentina, de 1903, Rodó se posiciona como favorável à manutenção da continuidade do espírito informante da tradição, uma vez que na América iniciava-se 
um processo de descaracterização das ideias e culturas e o surgimento de um cosmopolitismo sin norte.

Segundo Medardo Vitier (1945), Rodó buscava construir uma espécie de "vida interior" para a América-Hispânica. Almejava arte, ciência, moral, política de ideias, sinceridade religiosa. Portanto, uma confiança racionalista que envolvia a atmosfera da lição de Próspero. Entretanto, esquecia que estes países estavam fazendo tudo de uma vez: higiene, arte, comunicação e novela, escola pública e legislação trabalhista, códigos e reabilitação do índio. Tudo se juntava e se confundia; o indígena com a civilização branca, até as persistências coloniais mais vivazes e nocivas.

A mesma situação pode ser localizada na obra de Rodó; ele dizia que a linguagem gauchesca, ou indígena, não era apropriada para as grandes criações poéticas. Por mais que Bartolomé Hidalgo (1788-1822) mostrasse ser um poeta popular e democrático, reproduzia ou criava a "rude" linguagem dos gaúchos.

En su lugar, para Rodó, Hidalgo se mueve en la esfera "barbara" de las costumbres y del lenguaje, y "solo muy superficialmente reflejaba el sentimento popular". Rodó endendía por "pueblo" claro está, una homogénea abstracción compuesta de ciudadanos blancos, republicanos y de habla castiza (ROCCA, 2003, p. 106).

Rodó dizia que Hidalgo tentara interpretar na forma escrita o balbuceo da imaginação popular. Entretanto, estava inserido nas características locais e peculiares de um povo, inexpressivas para representar o continente como um todo.

Josefina Ludmer (2006) acentua que o gênero gauchesco está situado entre a passagem da delinquência à civilização, é um dos produtos desta passagem. O que define o gênero gauchesco é a língua como arma. A militarização do setor rural durante as guerras de independência no Rio da Prata, e o surgimento de um novo signo social, o gaúcho patriota, po- 
dem ser postulados como a base do gênero, na medida em que permitem o acesso ao registro verbal dos gaúchos ao estatuto de língua literária, sua única representação escrita. Não era este passado pertencente à América Latina que Rodó buscava, principalmente porque a representação deste gênero está na independência do continente com relação à antiga metrópole: sim o passado que a Europa havia deixado, a partir do qual ela conseguiu consolidar seus sistemas filosóficos. Conforme Belém de Castro Morales (1990):

La única via de progreso para la consolidación de una cultura americana sólidamente construida es la que se adentra en la asimilación profunda de valores occidentales que, por su signo positivo, constructivo, idealista, humanista y estético, pudieran iluminar los primeiros pasos de la expresión americana hacia una madura originalidad. (MORALES, 1990, p. 49).

Rodó, em texto intitulado Rumbos Nuevos, diz que, após o processo de independência, a América Latina havia se tornado órfã da pátria-mãe Espanha. Critica toda aquela "geração impaciente" que acreditara ser possível uma emancipação livre da metrópole, desviando o sentimento de tradição e de raça. Esta reflexão rodoniana retoma a resistência de muitos pensadores causada pela independência. Para José Luis Romero (1978), por trás da preocupação pela ordem, havia a percepção de que a Independência havia provocado a formação de uma nova sociedade, distinta da tradicional, de curso imprevisível e possivelmente repleta de perigos. O que mais reprovava nos independentistas era o fato de ignorarem o ponto de partida, a Espanha. 


\section{Cristianismo e classicismo}

Para Castro Morales (1990), Rodó localizou em dois momentos históricos o desenvolvimento coletivo das potencialidades humanas: no cristianismo primitivo e no classicismo grego. Pedro Henríquez Ureña afirmou, em La moda griega (1908), que desde o Renascimento até "nossos dias" a Europa intelectual suscitava a questão helênica. Além disso, alertava para o perigo das falsificações do passado, que invadiam a literatura, desnaturalizando as épocas clássicas. Quando Rodó retoma o cristianismo e o classicismo grego, não o faz de modo a atualizar estas correntes, sim são reflexões um tanto quanto descontextualizadas para a América Latina do Século XX. Para ele, a Grécia possuía o segredo da juventude inextinguível ${ }^{3}$.

No he de ser yo quien propenda a amenguar la autoridad con que Grecia preside en lo más bello y más sólido de nuestro pensamiento. Aquel Pueblo único produjo para la humanidad su obra cien veces gloriosa; y ella dura y durará por los siglos. Sin la persistencia de esta obra, el crisitianismo sería un veneno que consumiría hasta el último vestigio de la civilización. (RODÓ, 1957, p. 268).

Com relação a esta faceta do pensamento do autor em questão, José Luis Gómez-Matínez (1981), em seu texto intitulado Sociedad y Humanidad en Ariel: reflexiones ante uma nueva lectura, afirmou que um dos modelos de sociedade presente na Europa até o século XVIII foi o ateniense, o qual Rodó muito admirava. Nela os indivíduos permanecem, desde seu nascimento, independentemente de seus méritos, divididos em dois grandes grupos: escravos e cidadãos. Conforme o progresso social avança, sua complexidade permite que ao escravo se ofereça a liberdade e ser chamado de povo.

\footnotetext{
${ }^{3}$ No final da minha pesquisa de doutorado (2013), tive acesso aos originais dos escritos de Rodó, lotados na Biblioteca Nacional de Montevidéu, onde existe uma seção de arquivos literários. E encontrei a seguinte afirmação escrita por ele: Grecia: yo soy un ciudadano de tus tiempos remotos!
} 
Para Martínez, apenas com a Revolução Francesa e com a formação dos Estados Unidos aparece um novo conceito de sociedade, pautado na democracia; o que amplia as necessidades do indivíduo em seu duplo aspecto constituinte: corpo e espírito, de onde erigem seus direitos:

Así, pues, los conceptos de sociedad y humanidad, si bien relacionados íntimamente en la idea moderna de la democracia, poseen un origen y están animados por propósitos distintos. Rodó, sin embargo, a lo largo de su obra, y especialmente en Ariel, usa de ambos términos indistintamente. Ello le lleva a criticar la sociedad por no poseer ésta las características o los ideales de la humanidad. Y el modelo idealista que propone, que tanto ha influido en la Hispanoamérica del siglo XIX, está llamado, precisamente por la confusión de términos y, por tanto, de funciones al fracaso en su realización práctica (GÓMEZ-MARTíNEZ, 1981, p. 121).

A confusão daquilo que a sociedade deve proporcionar, que toma consciência de viver dentro de uma sociedade, deve participar nos ideais de humanidade; o que levaria a Rodó a uma errônea interpretação da relação entre sociedade e humanidade. Uma sociedade nunca estaria "definitivamente organizada", nem a humanidade é um produto da sociedade, sim dos indivíduos que a formam, uma vez que a função desta é a de nos proporcionar a matéria-prima, para que o indivíduo possa desenvolver suas qualidades elevadas em sua máxima potência.

Os traços de certo idealismo são aplicados na definição de sociedade por Rodó, o que evidencia a descontextualização histórica que ele vivenciava. Ao criticar os Estados Unidos pelo excesso de praticidade, de materialidade e de especialização, o faz, segundo o crítico, de maneira idealista, sem considerar o meio e a realidade daquele país. Com relação à posição de Rodó sobre o cristianismo, esta temática foi bastante debatida por ele no texto Liberalismo Y Jacobinismo (1906), publicado originalmente no jornal La Razón, quando travou um debate contra a decisão da 
Comissão Nacional de Caridade e beneficência de eliminar os crucifixos dos estabelecimentos que estavam sob sua administração, resultado natural das ideias liberais que atingiam o país.

A proposta de retirada dos crucifixos dos hospitais do Estado partiu do doutor Eugenio Largamilla, em 1906, que apresentou uma moção à Comissão Nacional de Beneficência Pública, que fora acatada e colocada em prática rapidamente. Segundo Monegal (1957), esta medida foi aprovada, mas o fato gerou comentários e críticas, além de manifestações de diferentes posicionamentos. Rodó encarou esta atitude como Jacobinista, pois se tratava em sua opinião, de um fato de extrema intolerância e incompreensão moral e histórica. Ele se declarava como um liberal e libre-pensador no que concerne à religiosidade. Para Rodó, os crucifixos possuem a mesma essência que o busto de Sócrates numa aula de filosofia, um Cervantes na aula de literatura. Tirá-los das paredes tratava-se de uma separação do passado com o futuro:

Esto es todo cuanto el mundo clásico ofrece como precedentes del sentimiento Cristiano de la caridad. La dominación espiritual de Grecia dio a la unidad romana el resplandor de las ideas, la selección de las costumbres, el timón del criterio, la aguja magnética del gusto; pero no le dio la regeneración moral. (RODÓ, 1957, p. 267).

Rodó acreditava na manutenção do crucifixo nos hospitais, escolas e outros ambientes públicos; conforme ele, teria o caráter de caridade, e mesmo num Estado laico não teria razão para serem retirados, pois o crucifixo possui significado próprio e histórico, e nem que representasse apenas o catolicismo que prevaleceu na Europa e que teria definido as nacionalidades Europeias, deveria ser retirado. Para ele, o sentido da obra intelectual do século XIX, em suma, foi a tolerância, principalmente a espiritual. Dizia-se adepto do livre-pensamento, inclusive religioso: 
En general, con esa tolerancia encaro cuanto leo, si reconozco en ello sinceridad: ya se trate de religión, de ciencia o de literatura. En la educación de mi espíritu, de una cosa estoy satisfecho; y es de haber conquistado, [...] aquella superior amplitud que permite al juicio y al sentimiento [...] (RODÓ, 1957, p. 291).

Para Auguste Comte, o catolicismo também cumpriu essa função; foi o responsável por conceber e concretizar uma educação de alcance universal, "intelectual, mas principalmente moral", que se estendia a todas as classes da população europeia, inclusive aos servos. Segundo Benoit (1999), Comte via como função do poder espiritual não apenas educar do ponto de vista moral, mas também aconselhar no que diz respeito aos atos da vida prática. Como se percebe, se a educação transfere ideologias, a confissão reforça a sua aplicação e, desse ponto de vista, esta prática religiosa deve ser vista, historicamente, como um poderoso instrumento de aperfeiçoamento social.

O poder espiritual teve seu alcance social aumentado com o dogma que atribui divindade "ao fundamento do catolicismo", Jesus Cristo. Na lição 54 de seu Curso de Filosofia Positiva, Comte afirma que o dogma católico da divindade de Jesus Cristo permitiu que esta doutrina estabelecesse a origem do poder espiritual como completamente autônoma e dotada, daí por diante, de uma genealogia própria e independente do poder temporal. O sacramento e a missa católica seriam rituais particularmente importantes no interior do culto católico. Foram eles que, na Idade Média, colocavam nas mãos do poder espiritual "importantes meios morais de ação individual e de união social", reforçando ainda mais a sua "obra política indireta".

O catolicismo ensinou a "moral universal" e neste conteúdo residiu, desde o começo, sua força política. O catolicismo deu à moral a supremacia social que antes era da política. Pela primeira vez na história da 
humanidade, um sistema social pode se combinar perfeitamente com um sistema moral universal. A teoria social de Comte vê no poder católico, distinto e separado do poder temporal, uma contribuição para aperfeiçoar sensivelmente a organização interna de cada país, uma vez que ele conduziu a humanidade a um patamar político mais elevado com sua concepção da divisão dos poderes temporal e espiritual, e ainda por ter produzido uma teoria da organização social mais perfeita, baseada sobretudo na moral. Portanto, o sistema católico feudal deveria ser tomado como modelo pela moderna teoria social.

A ideia da religião como um poderoso instrumento de aperfeiçoamento social, propagada por Comte, também ressoa na obra de Rodó, quando este diz que as revoluções morais não são obra de cultura, sim de educação humana, e a atitude da Comissão Nacional de Caridade, de tirar Cristo das paredes, tratava de uma separação brusca do passado com o futuro. Jesus Cristo representa, na sua visão, em nossa civilização, o fundamento da caridade. E seu nome seguiria sendo durante o futuro mais expansivo e avassalador na memória humana. A conservação do papel do cristianismo seria uma forma de recuperar a harmonia que a sociedade estava deixando para trás com o processo de modernização. Pensa a evolução intelectual e social da América Latina a partir de um processo de continuidade, sem saltos abruptos. Percebe na figura do Jesus Cristo um heroísmo orientador de épocas passadas e pretendeu retomá-lo no momento em que viveu. Gustavo Gallinal (1967) resume muito bem essa ideia de Rodó com relação à moral cristã herdada de Comte. Seria essa moral que qualquer espécie de saber deve resgatar, é o espírito científico que realça a colaboração entre os "humildes" e os "sábios", sendo o limite, a aristocracia espiritual que apenas alguns conseguem atingir.

Desse modo, Rodó expõe e soluciona o que Comte, em 1789, denominou de imensa questão de ordem. O conglomerado poderá ser a 
Sociologias, Porto Alegre, ano 17, no 40, set/dez 2015, p. 380-414

matéria de um povo, porém falta a alma. Multidão sem ideias seria pedestal de tiranias, seja mansa ou violenta, seria sempre negadora da liberdade e da verdadeira democracia. A fórmula definitiva de uma civilização não existe nas sociedades modernas, esta fórmula existiu somente das civilizações extintas.

\section{Espiritualidade e materialidade: governos distintos?}

Poucas vezes Rodó tratou em seus textos o tema do cotidiano; sua obra está circunscrita a uma série de problemas vitais; vale-se sempre de alusões como um recurso estilístico de afetividade, evitando a linguagem direta. Mas, em 1908, escreveu o texto Del trabajo obrero en el Uruguay, num momento marcado por grandes reivindicações trabalhistas e no contexto de apresentação do primeiro projeto que estabelecia as regulamentações trabalhistas do país, de 1906, no governo de José Batlle y Ordoñez (1856-1929). O Uruguai, nesse momento, seguia o processo de modernização iniciado no final do século XIX. Conforme Caetano e Rilla (1996), os dados da economia e da sociedade uruguaia de 900 permitem imaginar um marco relativamente favorável à experiência reformista. O país tinha uma frágil prosperidade, que supunha não só uma forma de relação com o mundo capitalista, mas, além disso, também passou por um período sem crises.

Um dado interessante é que em poucos países do mundo o processo imigratório teve uma transcendência tão crucial na primeira configuração da sociedade local, como é o caso do Uruguai. Muitos desses imigrantes integraram os quadros das classes dominantes do final do Século XIX; foram chamados de "pioneiros do progresso", cujos nomes, associados ao comércio ou à indústria nacional, perpetuam a nomenclatura urbana nas ruas, edifícios, bairros e praças. 
Uma lei de 1890 estabeleceu, pela primeira vez, o imigrante ideal para o país: honesto e apto para o trabalho; para tanto, negava-se a entrada de enfermos, mendigos, indivíduos que, por "vício orgânico" ou por deficiência física, fossem inábeis para o trabalho, os maiores de 60 anos; além disso, proibiu-se a imigração asiática e a africana. Para Rodó, la multitud, la masa anónima, no es nada por sí misma. Essa "multidão" poderia significar, ao mesmo tempo, um instrumento de barbárie ou de civilização, conforme a direção moral que lhe fosse oferecida. Apesar da formação da classe média uruguaia ter como característica fundamental o imigrante, este também influenciou nas origens do movimento sindical do país.

A sanção da lei que estabelecia a jornada de 8 horas de trabalho só foi possível após muitas greves, passeatas e reclamações para que o direito fosse conquistado. Segundo Yamandú Gonzales Sierra (1996), a nova forma de regulamentação do tempo de trabalho, posta em prática principalmente nas fábricas e oficinas, abriu, na vida dos assalariados, novas possibilidades de realização do tempo livre. Para tanto, os governantes, médicos e higienistas promoviam um disciplinamento social da vida urbana, dirigido sobretudo aos pobres, vistos como sujos, ignorantes, promíscuos e alcóolatras. As novas leis de disciplina deveriam ser objeto de profilaxias e controles médicos, ideológicos e políticos, para evitar a propagação de enfermidades do corpo e da sociedade.

Foi nesse momento que Rodó escreveu o artigo enfeixado no livro El mirador de Próspero. Reconhece a importância da limitação da jornada de trabalho, a proteção das mulheres e das crianças trabalhadoras, a indenização por acidentes, o descanso semanal, condições de higiene e seguridade, o direito à greve, etc. Reivindicações correspondentes a realidades que passam por um processo de evolução social e econômica. Levando em conta essa circunstância, questiona: 
Sociologias, Porto Alegre, ano 17, no 40, set/dez 2015, p. 380-414

Cabe preguntar todavía si este género de reivindicaciones, justificadas y oportunas en los países de avanzado desarrollo industrial, mantienen su oportunidad tratándose de pueblos que, como los de nuestra América, no han pasado aún del aprendizaje de la industria y están lejos del exceso pletórico de población que agrava y embrevece, en las viejas sociedades de Europa, las luchas entre una burguesía opulenta y un proletariado que se angustia en los extremos de la necesidad. (RODÓ, 1957, p. 639).

Rodó acreditava que estas reinvindicações fossem prematuras demais para seu país. Talvez pudéssemos pensar esse seu posicionamento como uma tentativa de não assumir o avanço do processo de modernização e da indústria, que segundo Rodó seria responsável por um cosmopolitismo incolor. $\mathrm{O}$ acesso ao mundo moderno e ocidental deveria ser atingido primeiramente através das ideias, e não da materialidade.

O tema da democracia é introduzido em Ariel (1900) com referência ao enfrentamento das concepções idealizadora e utilitária. Ela seria sinônimo de ascensão das massas e igualdade de possibilidades. Para ele, na América Latina o ideal político funciona como um precário fundamento sociocultural, sendo muitas vezes contraditório ou alheio às verdadeiras necessidades.

Desse modo, Rodó alerta para os possíveis perigos que poderiam ocorrer com o desenvolvimento orgânico do progresso industrial de seu país. Aqui podemos perceber uma espécie de deslocamento vivenciado por Rodó, diante dos sistemas de relações sociais que passava por mudanças cada vez mais aceleradas. Por isso, buscava redefinir seu papel no contexto conflitivo que passava a sociedade em que vivia. Para Barrán (2004), Rodó temia o predomínio do "número" sobre o "talento":

"La noción de las legítimas superioridades humanas", la admisión de "la jerarquía", era lo único que salvaría a la democracia que al enunciar el compartible principio de "la 
universalidad y la igualdad de los derechos", podía conducir al predominio innoble del número (BARRÁN, 2004, p. 63).

Nesse sentido, a elite seria importante para que as novas sociedades latino-americanas triunfassem, e essa elite não necessariamente se basearia em classes sociais, sim em valores intelectuais e morais. Conforme Mabel Moraña (2008), Rodó seguia as pegadas do pensamento comtiano ao enxergar a democracia como um princípio de ordem, cujo risco principal é a tendência à eliminação das diferenças naturais entre os homens, especialmente no que se refere à inteligência, virtude e sensibilidade. $\mathrm{O}$ progresso se assenta no predomínio dos melhores, na legitimação desta desigualdade. Na obra Ariel afirmou:

Augusto Comte ha señalado bien este peligro de las civilizaciones avanzadas. Un alto estado de perfeccionamiento social tiene para él un grave inconveniente en la facilidad con que suscita la aparición de espíritus deformados y estrechos; de espíritus "muy capaces bajo un aspecto único y monstruosamente ineptos bajo todos los otros". El empequeñecimiento de un cerebro humano por el comercio continuo de un solo género de ideas, por el ejercicio indefinido de un solo modo de actividad, es para Comte un resultado comparable a la mísera suerte del obrero a quien la división del trabajo de taller obliga a consumir en invariable operación de un detalle mecánico todas las energías de su vida (RODÓ, 1957, p. 209).

Conforme Benoit (1999), a desorganização social do começo do Século XIX também tinha como consequência, para Comte, a dissolução dos fatores espirituais, que levou: 1) à divagação completa das inteligências; 2) à ausência quase total de moral pública e privada; 3) à "preponderância social do ponto de vista puramente material" (utilidade imediata). Para Comte, a sociedade do começo do Século XIX reclamava urgentemente um poder espiritual que reinstaurasse a necessária ordem moral e intelectual e a conduzisse à "perfeição social possível". A ausên- 
cia de uma "moral conveniente" era o maior obstáculo para a conservação da hierarquia social necessária e para a manutenção da também necessária autoridade política.

A perfeição social consiste na harmonia entre as partes desiguais que compõe a sociedade humana e supõe, portanto, que os homens aceitem os "papeis desiguais" que lhe são designados pela natureza e pela sociedade. Rodó, quando discute a questão do trabalho fabril no Uruguai, afirmava a necessidade de se fomentar o espírito de associação profissional entre empregados e patrões para conter os conflitos e criar-se uma personalidade corporativa, que equilibre o direito de ambas as partes.

Outro aspecto realçado por Rodó neste artigo diz respeito ao trabalho noturno feminino, entendendo que o "verdadeiro lugar" e desempenho da mulher seria no interior do lar, realizando a função de formar, organizar e manter (principalmente) a unidade da família: la piedra sobre que descansan toda moralidad y todo orden social. A figura feminina teria a função afetiva e organizadora do íntimo do lar, o que instituiria a família como a verdadeira base moral da sociedade. Se as mulheres da população pobre também eram obrigadas a trabalhar para a conquista de uma maior renda familiar, "pelo menos" seu trabalho deveria ser realizado durante o dia, pois implicava numa consideração moral: El trabajo de la mujer, fuera de su casa, durante las horas de la noche, trastorna las más fundamentales condiciones de la vida doméstica y lleva fatalmente al abandono y desorganización de la família (RODÓ, 1957, p. 663).

A família, para Comte, era a primeira unidade política, além de ser a unidade fisiológica da espécie humana. A mulher era reconhecida como superior afetivamente, por isso poderia ser atribuída a ela a função moderadora da inteligência; já ao homem, a preeminência intelectual. As mulheres também deveriam cooperar na educação moral das massas populares. Segundo Comte, em seu Catecismo Positivista, desde a dentição 
até a puberdade, a educação doméstica começa a se sistematizar pela introdução gradual de uma série de estudos regulares, mas deve continuar sendo dirigida pela mãe, que poderá guiar os trabalhos estéticos, quando ela mesma tiver recebido a educação universal. Dispensadas da vida ativa, as mulheres devem se limitar ao estudo lógico, não científico, bastando uma lição por semana.

Na obra rodoniana há uma separação da sociedade em espíritos superiores e pessoas comuns. Deveria ser dever do Estado predispor meios capazes de provocar uniformemente a revelação das superioridades humanas, para prevenir as consequências do modelo norte-americano, para a América Latina: nivelamento da humanidade por baixo, a quantidade sobre a qualidade, e por fim, a degradação da dignidade da vida, que impedia o florescimento das atividades superiores do espírito. Rodó era partidário de um aristocracismo intelectual que pudesse conciliar passado e futuro, sem abrir mão da tradição.

Rodó traz, em suas reflexões, o grande impasse vivido pelo continente: as tendências desintegradoras da complexa unidade orgânica, provocadas pelo aceleramento histórico e por rupturas permanentes. Para que os países seguissem a continuidade estabelecida desde a colonização, era necessário defender a tradição, não uma ruptura sustentada por um radicalismo político-cultural. Ele priorizava uma evolução racional e orgânica, tanto socialmente quando individualmente.

O mesmo sentido de tradição presente em Comte, podemos lê-la em Rodó; possui o sentido de sequência, e cada ruptura poderia trazer a ideia de recomeço, podendo quebrar valores já acumulados. Nesse sentido, pertenceria inteiramente ao passado, como um corpo estático que se transmite a um receptor. Essa seria a chamada solidariedade histórica, que reside no fato de encontrarmos um elemento de inspiração de onde se podem extrair ensinamentos. 


\section{Considerações finais: a força continental indivisível}

Ao realizarmos esta retomada da presença de alguns aspectos do pensamento comtiano na obra de Rodó, não tivemos como objetivo dizer que o mesmo transferiu ou simplesmente aplicou as ideias do autor francês em seu projeto continental. O estudo puro e simples dos conteúdos ideológicos externos recebidos no nosso âmbito não possibilita a compreensão dos nossos problemas.

O ambiente intelectual finissecular, sob o qual escreveu Rodó, contribuiu de maneira intensa na configuração de seu pensamento; o engajamento em formar uma nação, a partir de sua realidade local, complexa e heterogênea, o conduziu à busca de paradigmas ideológicos, jurídicos e educacionais na Europa Moderna. Conforme Leopoldo Zea (1980), o instrumento, do qual se valeram muitos pensadores da América Latina deste período para realizar a grande passagem para a modernidade, foi o positivismo:

Habrá que hacerse de esta filosofía, que apropiarse de su sentido, tal será la expresión del positivismo en nuestra América. En un audaz y tremendo esfuerzo los latino-americanos intentarán deshacerse de sí mismos, de lo que han llegado a ser lo largo de una historia que no consideraban propia, de la historia que la colonización ibera les había impuesto para ser distintos. Esfuerzo extraordinario por arrancarse un alma que consideran extraña, por hacer suyo un espíritu que les era, simplemente, ajeno. Ajeno a sus propias experiencias, extraño a lo que habían sido y no querían seguir siendo. Extraño siempre por ello, yuxtapuesto a una realidad que, quiérase o no, era la única realidad con la que podría contarse para edificar sobre ella el mundo que se quería construir (ZEA, 1980, p.12).

Desse modo, percebemos como os paradigmas europeus continuavam servindo de guia para as novas nações formadas neste continente, 
mas a partir deste momento as teorias europeias seriam utilizadas como tentativa de solução dos problemas internos. A razão e a ciência se definiram como os grandes expoentes capazes de potencializar o ensejo do futuro, e ao absorvê-las como elementos intelectivos tornavam-se fé.

Segundo Raymond Aron (2002), a filosofia positivista criada por Augusto Comte (1798-1857) subordinava o futuro da sociedade às interpretações do passado, e a função da sociologia seria compreender o devir necessário, ou seja, indispensável e inevitável, da história, de modo a auxiliar a realização da ordem fundamental. Para Rodó, o equilíbrio e a ordem seriam conquistados a partir do saber elaborado, da alta cultura, da retomada dos valores espanhóis perdidos, e do freamento das atividades atreladas à indústria.

A influência do positivismo em Rodó pode ser percebida de acordo com a obra do próprio Comte. Este, segundo Aron (2002), teria três "etapas" em seu pensamento. A primeira, de 1820 a 1826, estaria nos Opúsculos de filosofia social, em que reflete sobre os problemas sociais de seu tempo: a passagem do modo de pensar teológico para o modo de pensar laico. A sociedade que nasce passa a ser científica e a que morre, atrelada à Igreja Católica. Por isso, a necessidade da reforma intelectual. A segunda etapa, de 1830 a 1842, seria a do Curso de Filosofia Positiva, cujas ideias e diretrizes são as mesmas, mas a perspectiva é ampliada, momento em que estabelece a lei dos três estados. Nesse momento, percebe que, para compreender a evolução da sociedade francesa era necessário compreender a totalidade da história da espécie humana, considerada como unidade, elemento analítico indispensável para a compreensão das funções particulares do todo social e de um momento particular do devir. Neste curso, Comte cria a nova ciência, a Sociologia, que pretende analisar a evolução da espécie humana. O terceiro tema fundamental de Comte é o do Sistema de Política Positiva, de 1851 a 1854, momento em que con- 
solida sua "física social", bem como o catecismo positivista, e reafirma a necessidade ordenada da indústria e do progresso material. A partir deste instante, o filósofo francês tem a convicção de que os cientistas e os industriais dominariam a sociedade moderna erigida a partir do século XIX.

Entendemos que, no pensamento de Rodó, o positivismo apresenta-se, na maioria das vezes, conforme às primeiras "etapas" da teoria comteana: uma visão generalizada sobre a sociedade Latino-Americana, vista como conjunto uno e indivisível, a organização mental, importância da atividade intelectual, especialização do saber intelectual como responsável pela avaliação da história progressiva do espírito humano, o conhecimento como intervenção social, ausência de oposição entre a ciência e a religião, uma vez que elas não disputariam o mesmo campo do saber. Por fim, o sentimento de origem: todos os povos do continente descenderiam de uma única matriz, a Ibérica, por isso a necessidade de mantê-la como influência totalizante e amálgama das culturas.

Fernando Henrique Cardoso (1980), em seu conhecido texto intitulado Originalidade da Cópia: a CEPAL e a ideia de desenvolvimento, afirma que, entre os críticos da cultura na América Latina, existe um debate intermitente sobre os efeitos da dependência sobre a produção das ideias. Tais críticos buscam mostrar que a mesma ideia, uma vez transferida dos centros de produção internacional de cultura para a periferia, torna-se outra coisa. Cita a análise de João Cruz Costa (1904-1978) sobre a transferência do positivismo para a América Latina, onde adquiriu a ideia de progresso, tornando-a uma ideologia de cunho mais reformista do que reacionário. Esta ideologia continha diversos projetos civilizadores, assim, o positivismo tornou-se paladino da ideia de progresso.

José Luis Romero, em Situaciones e ideologías en América Latina (2001), também afirmou que, apesar de considerar as relações entre América Latina e Europa como produto de um largo processo de acul- 
turação e europeização, insiste em toda sua obra o caráter autônomo e particular do comportamento social e político latino-americano nos diferentes períodos e etapas de sua história. O estudo dos conteúdos ideológicos externos recebidos possibilita a compreensão dos nossos problemas. Entretanto, da forma como afirmou Richard Morse (1982) em O Espelho de Próspero, a metáfora do espelho resultaria de uma imagem invertida das fontes da civilização ocidental, familiares ao nosso continente, porém, seus legados específicos correspondem a um anverso ou um reverso.

Christian Lynch (2013) retomou essas questões sobre a ideia de origem das teorias que chegaram à América Latina, e afirmou que o pensamento produzido pelo "novo mundo" é visto como periférico, e isso seria consequência de um regime eurocêntrico e evolucionista de historicidade. A ideia predominante é que ocuparíamos uma temporalidade atrasada em relação aos países do "velho mundo"; começamos a criar ideias, pensamentos muito tempo depois, quando a Europa já havia iniciado tal processo, que originou suas principais teorias ${ }^{4}$.

Nesse sentido, as nações periféricas estavam, aos olhos do centro, numa condição "atrasada" e "anormal". Quando a América Latina internaliza essa condição de inferioridade, na forma de um sentimento de exclusão do "mundo civilizado", ou de inserção nele sob a condição subalterna, surge toda uma reflexão, como aquela realizada por Rodó, que tenta "unir forças" elaborando a ideia de indivisibilidade continental. A herança positivista presente em Rodó tem como ponto importante essa concepção de retorno ao passado para pensar o futuro de seus países.

\footnotetext{
${ }^{4}$ Nesse trabalho mencionado Lynch ressalta que a reflexão política brasileira e latino-americana em geral, é sempre encarada como pensamento, e não teoria. Sua hipótese aventada é a de que no Brasil suas elites sempre consideraram seus produtos intelectuais mais ou menos inferiores dos desenvolvidos na Europa e Nos Estados Unidos. Os textos teóricos ou filosóficos seriam mais coerentes, abrangentes e abstratos, já aqueles que aparecem sob a rubrica "pensamento", seriam fragmentários, contingentes ou assistemáticos.
} 
Sociologias, Porto Alegre, ano 17, no 40, set/dez 2015, p. 380-414

Comte nasceu na França num momento de grande instabilidade política e social, por isso uma de suas bandeiras era a reconciliação da ordem e do progresso, elementos capazes de oferecer a compreensão do equilíbrio para a progressão histórica da sociedade francesa, vista como paradigma para o mundo moderno.

No pensador analisado aqui, notamos que a ideia de futuro é frequente, e o passado poderia auxiliar na compreensão dos principais problemas do continente Latino-Americano. Entretanto, a solução para tais problemas somente poderia ocorrer numa temporalidade vindoura. Por isso, a necessidade da busca de um equilíbrio. A estrutura significativa com que Comte formulou sua teoria é distinta da de Rodó, mas nossa tentativa foi demonstrar que o pensador retoma muitas tendências do pensamento comtiano, os quais, por conta de sua amplitude, não foram retomados por outros, como por exemplo: a resistência às mudanças abruptas, a defesa da ordem associada a uma teoria que defendia a supremacia do poder espiritual sobre o humano, a formação de um Estado católico que apoiava e defendia a Igreja como garantia da ordem, a negação do processo de secularização da sociedade civil e, por fim, a sociedade nivelada a partir dos altos poderes espirituais, não materiais e mundanos.

Elisângela da Silva Santos é Professora da área de Sociologia e Fundamentos do curso de Pedagogia da Universidade Federal de Goiás, Regional Jataí. \licass20@yahoo.com.br

\section{Referências}

1. ARDAO, Arturo. Etapas de la inteligencia uruguaya. Montevideo: Departamento de publicaciones de la Universidad de la Republica, 1971.

2. ARDAO, Arturo. Espiritualismo y positivismo en el Uruguay. Montevideo: Departamento de publicaciones de la Universidad de la Republica, 1968.

3. ARON, Raymond. As etapas do pensamento sociológico. São Paulo: Martins Fontes, 2002. 
4. BARRÁN, José Pedro. Los conservadores uruguayos (1870-1933). Montevideo: Ediciones de la Banda Oriental, 2004.

5. BENOIT, Lelita Oliveira. Sociologia comteana. São Paulo: FAPESP/Discurso Editorial, 1999.

6. CAETANO, Geraldo; RILLA José. Historia Contemporánea del Uruguay: de la colonia al mercosur. Montevideo: Fin de siglo, 1996.

7. CARDOSO, F. H. Originalidade da cópia: a CEPAL e a ideia de desenvolvimento. In: As ideias e seu lugar: ensaios sobre as teorias do desenvolvimento. Petrópolis: Vozes, 1995, p.27-80.

8. COSTA, João Cruz. Contribuição à história das ideias filosóficas no Brasil: o desenvolvimento da filosofia no Brasil e a evolução histórica nacional. Rio de Janeiro: Livraria José Olympio, 1956.

9. CUNEO, Dardo. Sarmiento y Unamuno. Salamanca: Ediciones Universidad de Salamanca, 1997.

10. FELDE, Alberto Zum. Estetica del novecentos: conferencias dadas en la Facultad de Humanidades de La Plata en setiembre de 1927. Buenos Aires: El Ateneo, 1927.

11. FORACCHI, Maria Alice (org.). Karl Mannheim: sociologia. São Paulo: Ática, 1982.

12. GALLINAL, Gustavo. Letras Uruguayas. Montevideo: Colección de clásicos uruguayos de la Biblioteca Artigas, 1967.

13. GARZÓN, Fernando Mañe. Un siglo de darwinismo: un ensayo sobre la historia del pensamiento biológico en el Uruguay. Montevideo: Facultad de Medicina, Sección Historia de la medicina, 1990.

14. GOMEZ-MARTINEZ, José Luis. Sociedad y humanidade en Ariel: Reflexiones ante una nueva lectura. In: Texto/contexto en la literatura iberoamericana. Memoria del XIX Congreso. Madrid: Artes Gráficas Benzal, 1981, p. 117-127.

15. LYNCH, Christian Edward Cyril. Por que pensamento e não teoria?: a imaginação político-social brasileira e o fantasma da condição periférica (18801970). Dados, Rio de Janeiro, v.56, n.4, p.727-767, dezembro de 2013. Disponível em: http://www.scielo.br/scielo.php?script=sci arttext\&pid=S0011-

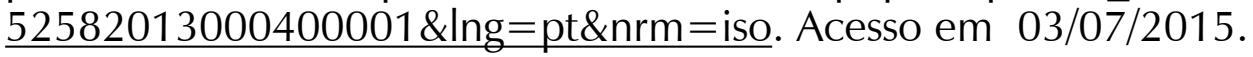

16. LUDMER, Josefina. El género gauchesco. In: ECHEVARRÍA, R.G.; PUPO,W. (eds.). Historia de la literatura hispanoamericana: del descubrimiento al modernismo. Madrid: Gredos, 2006. p. 614-629. 
Sociologias, Porto Alegre, ano 17, no 40, set/dez 2015, p. 380-414

17. MORALES, María Belén de Castro. Eclecticismo y modernismo en José Enrique Rodó y su generación. Revista de Filología, Universidad de la Laguna, n.6 y 7, p.119-130, 1987-88.

18. MORALES, María Belén de Castro. José Enrique Rodó Modernista. Utopia y regeneración. Isla Canárias: Universidad de la Laguna, 1990.

19. MORAÑA, Mabel. José Enrique Rodó. In: ECHEVARRÍA, R.G.; PUPO,W. (eds.). Historia de la literatura hispanoamericana: del descubrimiento al modernismo. Madrid: Gredos, 2008. p. 655-665.

20. MORSE, Richard. O multiverso da identidade latino-americana. In: Leslie (org.). História da América Latina: A América Latina após 1930: Ideias, cultura e sociedade. BETHELL. São Paulo: Edusp, 2011.

21. MORSE, Richard. O espelho de Próspero: cultura e ideias nas Américas. São Paulo: Companhia das Letras, 1982.

22. MONEGAL, Emir Rodríguez. Prefacio. In: José Enrique Rodó: Obras Completas. Madrid: Aguilar, 1957.

23. MONEGAL, Emir Rodríguez. José Enrique Rodó en el novecentos. Montevideo: Número, 1950.

24. OLIVEIRA, Lúcia Lippi. A questão nacional na Primeira República. São Paulo: Brasiliense. Brasília: CNPQ, 1990.

25. ROCCA, Pablo. Poesía y Política en el siglo XIX: un problema de fronteras. Montevideo: Ediciones de la Banda Oriental, 2003.

26. RODÓ, José E. Ariel. Motivos de Proteo. Caracas: Biblioteca Ayacucho, 1976.

27. RODÓ, José E. El mirador de Próspero. Madrid: Biblioteca Andrés Bello, 19

28. RODÓ, José E. Obras Completas. Compilación, prólogos y notas de MONEGAL, Emir Rodríguez. Madrid: Aguilar, 1957.

29. ROMERO, José Luis. Situaciones e ideologías en América Latina. Medellín: Universidad de Antioquia, Colección Clásicos del Pensamiento Hispanoamericano, 2001.

30. ROMERO, José Luis. Prólogo. Pensamento conservador (1815-1898). Caracas: Biblioteca Ayacucho, 1978.

31. SABAT, Juan Carlos Pebet. Rodó en la cátedra. Montevideo: Publicación de la Asociación José Enrique Rodó, 1931. 
32. SIERRA, Yamandú Gonzáles. Domingos obreros en los albores del siglo XX: itinerarios del tiempo libre. In CAETANO, Geraldo; PORZECANSKI, Teresa (eds.). Historia de la vida privada en el Uruguay: El nacimiento de la intimidad (18701920). V.2, p. 201-228, 1996.

33. UREÑA, Pedro Henríquez. La utopia de América. Caracas: Biblioteca Ayacucho, 1978.

34. VITIER, Medardo. Del ensayo americano. México: Fondo de cultura económica, 1945.

35. WEFFORT, Francisco. A América Errada: notas sobre a democracia e a modernidade na América Latina em crise. Lua Nova. São Paulo, N.21, p.5-40, Setembro 1990.

36. ZALDUMBIDE, Gonzalo. Estudio preliminar a Ariel. In: Ariel. Montevideo: Ediciones del Nuevo Mundo, p. 11-58, 1967.

37. ZEA, Leopoldo. Discurso desde a marginalização e a barbárie. Rio de Janeiro: Garamond, 2005.

38. ZEA, Leopoldo. Pensamiento positivista latinoamericano. Caracas: Biblioteca Ayacucho, 1980.

Recebido em: 07/12/2014

Aceite final em: 10/05/2015 